Images dans le monde ibérique et ibéricoaméricain

$8 \mid 2015$

L'Histoire et ses récits entre images, fictions et paratextes

\title{
El espacio marginal como núcleo autorreferencial (retórico, compositivo, conceptual) en La pícara Justina
}

Marta Cuenca-Godbert

\section{(2) OpenEdition \\ Journals}

\section{Edición electrónica}

URL: http://journals.openedition.org/agedor/473

DOI: 10.4000 /agedor.473

ISSN: 2104-3353

\section{Editor}

Laboratoire LISAA

Referencia electrónica

Marta Cuenca-Godbert, « El espacio marginal como núcleo autorreferencial (retórico, compositivo, conceptual) en La pícara Justina », L'Ấge d'or [En línea], 8| 2015, Publicado el 01 febrero 2016, consultado el 30 abril 2019. URL : http://journals.openedition.org/agedor/473 ; DOI : 10.4000/ agedor. 473 


\title{
El espacio marginal como núcleo autorreferencial (retórico, compositivo, conceptual) en La pícara Justina
}

\begin{abstract}
Résumé : La picara Justina de Francisco López de Úbeda offre une explosion de virtualités textuelles. La fragmentation constitue l'une des caractéristiques formelles fondamentales de l'œuvre, véritable corpus de poèmes, de textes en prose, de paragraphes conclusifs moralisateurs, de notes à la marge; autant de formes d'écriture combinées entre elles en un puzzle singulier. Nous explorons les notes marginales en tant que fil d'Ariane dans le labyrinthe de l'œuvre. Son histoire éditoriale permettra d'apporter un éclairage génétique aux notes. La présence des marginalia dans toutes les éditions du livre place l'autoréflexion au centre de la composition rhétorique de l'ensemble. L'instance narrative qui produit l'ensemble des textes apparaît de manière multiple, comme en diffraction. L'effet de style que produit l'inclusion des annotations, partie intégrante de l'œuvre, invite par ailleurs à considérer leur motivation au second degré : elles constituent un reflet du caractère marginal de la substance narrative. Ainsi s'offre-t-elle au lecteur s'il se montre disposé à mettre en question le caractère linéaire de la lecture.
\end{abstract}

Mots-clés : Pícara - marges - marginal - hypertextualité - fragmentation - annotation - autoréférentialité

Resumen: La picara Justina de Francisco López de Úbeda ofrece una explosión de virtualidades textuales. Una de las características formales fundamentales del libro es su fragmentación, ya que se trata de un verdadero corpus, compuesto de poemas, prosas, aprovechamientos, notas marginales, formas de escritura de diversa índole combinadas entre sí en un curioso puzle. La apuesta de lectura consiste en explorar los apuntes marginales como uno de los hilos de Ariadna en el laberinto de la obra. Un repaso a la historia y fortuna editorial de la obra permitirá una aproximación genética a dichas notas. La fijación editorial de los marginalia los acuña como fruto de un proceso autorreflexivo dentro de la composición retórica del conjunto. La instancia narrativa de la que emanan los textos parece múltiple y como difractada. El efecto estilístico de la inclusión de las notas como parte íntegra de la obra invita además a considerarlas como una motivación en segundo grado: las notas marginales son un reflejo de lo marginal como sustancia narrativa. Como tal se ofrece al lector, a poco que éste se preste a romper con una lectura lineal.

Palabras clave: Pícara - márgenes - marginal - hipervinculación - fragmentación - apostilla autorreferencialidad

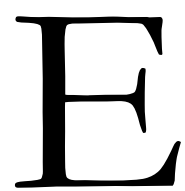
ntre la producción narrativa aurisecular, La picara Justina de Francisco López de Úbeda ofrece una explosión de virtualidades textuales. Una de las características formales fundamentales del libro es su fragmentación, en formas de escritura de diversa índole combinadas entre sí en un curioso puzle. El presente trabajo propone explorar los apuntes marginales que figuran en las ediciones como uno de los hilos de Ariadna en el laberinto de la obra.

Un repaso a la trayectoria editorial de la obra es una etapa necesaria para aproximarnos a lo específico de dichas notas. Desde la edición prínceps de 1604, las notas marginales aparecen como parte de la obra ${ }^{1}$. No se cuestiona que sean fruto de la intención del propio autor, de modo

\footnotetext{
${ }^{1}$ Paloma López de Tamargo indica que «muchos editores han considerado [las glosas o apostillas al margen] como superfluas y [las] han omitido», evocando las ediciones de la Biblioteca de Autores Españoles o la de Aguilar. Utiliza
} 
que pertenecen plenamente a la obra así como los diferentes elementos de un aparato paratextual complejo en el que se incluyen también versos catalogados en una Tabla con explícita voluntad enciclopédica ${ }^{2}$. Se multiplican las indicaciones estructurales, como lo reflejan los títulos de los diferentes libros: «La pícara montañesa», «La pícara romera», «De la pícara pleitista», «De la pícara novia», en los cuales los diferentes epítetos homéricos dan a ver el esquema de la trayectoria de la protagonista (orígenes, viajes, confrontaciones, casamiento), conforme con el programa picaresco.

Entre los elementos novelescos, desconectados por tanta fragmentación, y la voluntad de crear un marco de lectura aparece un desfase. Si Antonio Rey Hazas apunta que «el desorden preside el desarrollo de esta obra, cuyos elementos novelescos están evidentemente deshilvanados» ${ }^{3}$, la desconexión entre los elementos novelescos podría deberse a la profusión de hilos retóricos. La ausencia de linealidad perturba la lectura diegética pero invita a otras. Lo que hilvana literalmente el texto bien pueden ser los apuntes marginales, que proponen una diseminación lectora. La evaluación crítica a la que han sido sometidas las apostillas ha ido evolucionando, desde los estudiosos que destacan en ellas los aspectos redundantes (indicando su valor de resumen o anticipación), hasta los que abogan por brindarles el papel de esqueleto narrativo, o por la posibilidad de combinar ambas posturas. Más allá de la lectura simultánea o complementaria de las apostillas, aparece la posibilidad de una lectura enlazada, anclada en el propio texto y apuntando hacia otros textos.

La fijación editorial de los marginalia los acuña como fruto de un proceso autorreflexivo dentro de la composición retórica del conjunto. En la propia obra, se multiplican las instancias narrativas pero la voz de la que emanan las apostillas es la voz autorial. El efecto estilístico de la

la edición de Antonio Rey Hazas en la que sí se reproducen, lo cual le parece un elemento clave ya que para ella forman parte del «paratexto» así como los prólogos, los poemas y los aprovechamientos (LÓPEZ DE TAMARGO, Paloma, «Cuadros y recuadros del discurso picaresco: el caso de La Pícara Justina», in Actas del VIII Congreso Internacional de Hispanistas, 1983, p. 195, URL: http://cvc.cervantes.es/literatura/aih/pdf/08 $\angle$ aih $08 \quad 2$ 025.pdf).

David Mañero Lozano hace un inventario de las ediciones de la Pícara Justina existentes. Entre las ediciones mencionadas, las traducciones-adaptaciones extranjeras manipulan las apostillas, como por ejemplo la francesa que las elimina o las utiliza para explicar términos dejados en castellano (MANERO LOZANO, David, «Trayectoria editorial de La pícara Justina. Estudio bibliográfico y textual», in Criticón, 109, 2010, p. 73-93, URL: http://cvc.cervantes.es/literatura/criticon/PDF/109/109 073.pdf). El mismo estudioso coteja once ejemplares de la edición prínceps (MAÑERO LOZANO, David, «La edición príncipe de La pícara Justina. Análisis de estados textuales», in Revista de Literatura, n. 146, julio-diciembre, vol. LXXIII, 2011, p. 407-426, URL: http://dialnet.unirioja.es/servlet/articulo?codigo=3811513). En uno de los pliegos de uno de los ejemplares se olvidan las apostillas marginales y se observa la técnica de los impresores para subsanar el error, aprovechando para corregir errores tipográficos pero generando otros. Se deduce la posible participación del autor en el proceso de impresión (art. cit., p. 12).

2 «Tabla desta arte poética en que se ponen todas las especies y diferencias de versos que hasta hoy hay inventados, los cuales están en este libro repartidos en los principios de los números». (LÓPEZ DE ÚBEDA, Francisco, La picara Justina, edición de David Mañero Lozano, Madrid, Cátedra, 2012, p. 163. Edición de referencia, a la cual corresponderán las demás citas de la obra salvo mención contraria (se apuntará La pícara Justina, p. xxx).

${ }^{3}$ LÓPEZ DE ÚBEDA, Francisco, La picara Justina, edición de Antonio Rey Hazas, Madrid, Editora Nacional, 1977, p. 24-25.

${ }^{4}$ José Antonio Calzón García dedica una parte de su tesis doctoral a las notas marginales, citando los trabajos de Paloma López de Tamargo (art. cit.) y José Miguel Oltra Tomás que plantean «el valor contrastivo y complementario» de las notas, mientras Juan I. Ferreras Tascón «insiste en que estas anotaciones van indicando con mucho acierto, por no decir precisión, el contenido de la obra» (CALZÓN GARCÍA, José Antonio, Enunciación, alteridad y polifonía en La pícara Justina, Tesis doctoral, Universidad de Oviedo, Facultad de Filología, Departamento de Filología Española, 2007, URL: http://dialnet.unirioja.es/servlet/tesis?codigo=18381 „p. 98-99). Calzón García subraya la «voz particular» de las apostillas dentro de la obra (op. cit., p. 99). Una serie de cuadros en los que se establece la correspondencia formal entre texto en prosa y notas marginales muestran cómo las notas pueden corresponder a fragmentos que emanan tanto de la voz narrativa como de la de personajes, retomando literalmente expresiones de una forma a otra del texto, incidiendo en las acciones o en los pensamientos. Se identifican además una serie de mecanismos para dar a ver la función de «intentar facilitar la compresión del texto» (op. cit., p. 99 a 106). 
inclusión de las notas como parte íntegra de la obra invita además a considerar una motivación en segundo grado: las notas marginales son un reflejo de lo marginal como sustancia narrativa.

\section{Acotaciones retóricas, firmas del autor}

Dentro de este puzle textual, las apostillas, atendiendo a su sentido literal, se convierten en acotaciones que orientan la lectura del texto. Mediante los apuntes marginales la puesta en escena de la escritura obedece a los preceptos de la retórica en su división canónica en cinco etapas. Según se considere una(s) u otra(s) de las etapas de la construcción del discurso retórico en el proceso creador, el punto de vista no es el mismo: o son las apostillas un esquema del soporte inicial del discurso luego desarrollado (inventio, dispositio - encontrar el tema y organizar la cadena discursiva); o bien se trata de un apunte a posteriori para ofrecer un resumen (memoria, actio catalogar y hacer resaltar los momentos). En la tradición, las apostillas aparecen necesariamente ${ }^{5}$ después, emanen de un comentarista externo a la obra, o del propio autor en un proceso de repaso. Lo curioso aquí es que estas notas marginales aparecen desde la primera edición de la obra, dentro del proceso organizativo decidido por el propio autor. Desde esta perspectiva organizativa, la parte central (elocutio), punto de articulación entre la construcción del discurso escrito y su vocación a cumplir con la intención persuasiva, podría materializarse en los apuntes marginales, destinados a reproducir el soporte retórico. La colocación de las apostillas ofrece una posibilidad de lectura vertical paralela, como un guión.

La posición física de las apostillas, texto al lado del texto, sirve de hilo conductor en la página. Empíricamente, aparecen al ojo lector como una forma de encauzar la lectura por su frecuencia y su brevedad. El sistema que se pone en marcha desde la «Introducción General» obedece al esquema siguiente: SECCIÓN + título, NÚMERO + título, FORMA POÉTICA + poema (con apostilla «Suma del número»), texto en prosa (con varias apostillas), APROVECHAMIENTO + prosa breve. Y así sucesivamente hasta el último capítulo. Dentro de esta organización, las notas jalonan los textos.

La primera de las notas aparece en el apartado titular de la Introducción General, junto a la mención «Divídese esta introducción en tres números»: «Es tan artificiosa introducción, que con su ingenio capta la benevolencia a los discretos, y con su dificultad despide, desde luego, a los ignorantes». ${ }^{6}$ La nota menciona explícitamente a la etapa retórica de la captatio benevolentiae en esta parte introductora y atiende a los tópicos de alabanza de los discretos y menosprecio de los ignorantes, aprovechando el autor la ocasión para jugar con el tópico de la modestia calificando la introducción «artificiosa» y recalcando su «ingenio». Más allá del apunte funcional, se trata de suscitar el interés del lector gracias a la presencia de las notas.

El único caso en que otro título se acompaña de un apunte es el del número segundo («Del melindre a la mancha», momento en que Justina lamenta haberse manchado con la tinta con la que escribe, lo que da pie a una serie de juegos verbales): «A propósito de la mancha de la saya, prosigue artificiosamente el autor la introducción de su libro.. $\rangle^{7} \mathrm{El}$ apunte marginal redunda en el quehacer del autor, a la manera de algún comentarista exterior, pero es el propio autor el que lo escribe, con el único interés de añadir que el que escribe lo hace «artificiosamente». Aparte de las redundancias que mencionan «la mancha», objeto de la escritura, y el hecho de que seguimos en «la introducción», se indica explícitamente que el texto es pura creación que emana de una instancia autorial única. La manera de proceder, el estilo «artificioso», esto es becho con arte, la reivindica el

\footnotetext{
5 Apostillar. v. a. Hacer notas breves y sacarlas al margen de algún libro, o escrito, sobre lo que en él se dice, Real Academia Española, Diccionario de Autoridades, Tomo I (1726), URL: http://web.frl.es/DA.html.

${ }^{6}$ La picara Justina, p. 197.

${ }^{7}$ Ibid., p. 223.
} 
autor como suya. De esta forma, la identidad del autor aparece reflejada constantemente en el texto, no sólo en los documentos liminares paratextuales (con la mención explícita de su nombre en cubierta, en el Privilegio y la Aprobación, o la expresión en primera persona en la Dedicatoria y en los Prólogos), sino incluso en el desarrollo de libro en el que recuerda su intervención de organizador supremo del discurso mediante las apostillas.

En la organización de las notas, el único automatismo lo constituye la mención de «Suma del número» que aparece junto a todas las formas poéticas, indicando su dimensión programática. Los aprovechamientos, que ya pueden considerarse glosas de los capítulos, carecen de apostillas, salvo el del Número Primero del Capítulo Primero, en el cual se hace una curiosa mención del «Auton ${ }^{8}$ :

\author{
APROVECHAMIENTO \\ Concedió a los hombres el Autor de naturaleza la politica comunicación de \\ palabras, y el uso dellas para ayudarse unos a otros en las miserias desta \\ trabajosa peregrinación, para pedirse socorro en los trabajos, para alentar \\ Cuál sea el fin de bablar \\ el amor del prójimo y de Dios, último bien nuestro. \\ Pero los hombres ignorantes y viciosos adulteran la lengua y las palabras, \\ usando dellas para comunicar entre sí mismos cosas frusleras y vanas, más \\ proprias para calladas que dignas de salir a lu₹. [...] \\ Abuso de las conversaciones
}

La glosa del aprovechamiento ilustra el funcionamiento de la ficción como parábola sugiriendo un paralelo entre el Autor y el Creador. Dios («el Autor de naturaleza») le dio al hombre el lenguaje («la politica comunicación de palabras»), pero el hombre «abus[a] de las conversaciones», malgastando el don («cosas frusleras y vanas»). El autor de ficción, esta vez sin mayúscula ${ }^{9}$, da la palabra a sus personajes, que abusan de ella, pero la instancia superior de la narración está presente para sacar la lección. En un texto en el cual el autor ha delegado plenamente la palabra a su personaje, cronista de su propia vida, las notas marginales dan a ver que aquél pretende conservar cierto control de la materia narrativa, para canalizarla y dar a ver su dimensión de exemplum. Parece que el flujo de la prosa necesitase, para el autor, el apoyo visible de una fórmula breve, no ya para progresar o avanzar, sino para que el texto vuelva constantemente sobre sí mismo en una forma de autorreflexividad constante.

\footnotetext{
${ }^{8}$ Ibid., p. 296.

${ }^{9}$ Se establece una diferenciación entre el «autor», mención autorreferencial, y el «Auton» con mayúscula, calificado de «natural» (de forma parecida al «Autor de naturaleza» en la cita comentada) en el Prólogo al lector: «...a un hombre cuerdo y honesto, aunque no le entretienen leturas de amores deshonestos, pero enredos de hurtillos graciosos le dan gusto, sin dispendio de su gravedad, en especial con el aditamento de la resumpción y moralidad que tengo dicho. Y deste modo de escribir no soy yo el primer autor, pues la lengua latina, entre aquellos a quien era materna, tiene estampado mucho desto, como se verá en Terencio, Marcial y otros, a quien han dado benévolo oído muchos hombres cuerdos, sabios y honestos. Pienso que los que así escriben, añadiendo semejantes resumptiones a historias frívolas y vanas, imitan en parte al Autor natural, que de la nieve helada y despegadiza saca lana cálida y continuada, y de la niebla húmeda saca ceniza seca, y del duro y desabrido cristal saca menudos y blandos bocados de pan suave.», La picara Justina, p. 183. En el momento en que López de Úbeda defiende sus opciones de escritura, junto con los argumentos de autoridad de los latinos, se pone en paralelo con «el Autor natural» que saca orden del desorden y bienes de los males. Son las únicas menciones del «Autor» en todo el libro.
} 


\section{Hilo conductor narrativo-compositivo}

Aparte de la circularidad a la que remite el esquema organizativo que culmina en el recuento moral, la identificación genérica con la picaresca supone una progresión desde un estado inicial en la vida del protagonista hasta un estado final, proponiendo al lector sacar una lección de las andanzas. Observemos la puesta en marcha de la intriga en el Libro Primero titulado «La Pícara Montañesa» ${ }^{10}$. La identificación del personaje principal reincide en la utilización del sustantivo «Pícara» (después de la identificación onomástica «Justina» ya desde el título) que junto con el adjetivo «montañesa» genera una expectativa inmediata: la del desarrollo de los orígenes, etapa inicial canónica. Sin embargo, lo que se ofrece al lector es una serie de consideraciones sobre el arte de escribir un personaje su propia vida, cuestionando su papel de cronista. Proliferan también los locutores, descentrando del mismo modo el papel esperado de la protagonista narradora en primera persona.

El desvío del programa narrativo se anuncia desde los títulos:

\section{CAPÍTULO PRIMERO}

De la escribana fisgada

NÚMERO PRIMERO

Del fisgón medroso ${ }^{11}$

Si el primer título indica que la que escribe está siendo observada, es para centrarse seguidamente en el que la observa (de «fisgada» a «fisgón»), invirtiendo la importancia de las acciones: no importa tanto el que escribe como el que mira.

En el poema inicial una voz introduce a Justina y Perlícaro («Al comenzar Justina, entró Perlícaro» ${ }^{12}$, junto a estas palabras, aparece la apostilla $« D a$ vaya ${ }^{13}$ un fisgón a Justina, sobre que se hace cronista de su vida» que emana de la misma voz en tercera persona. Cuando comienza el texto en prosa, se introduce del mismo modo el nacimiento de Justina en tercera persona: «Nació Justina Díez, la pícara, el año de las nacidas, que fue bisesto, a los seis de agosto, en el signo Virgo, a las seis de la boballa» ${ }^{14}$. Acto seguido, ésta toma la palabra en un punto y aparte: « ¿Ya soy nacida? ¡Ox, que hace frío» ${ }^{15}$. Pero en lugar de contar su vida pone en escena un debate animado entre ella misma y Perlícaro el fisgón, a propósito del cual expone una serie de motivaciones onomásticas ${ }^{16}$ :

de perla por su hermosura, y el de Ícaro por la alteza de su redomada sabiondez. Mejor me parece a mí que fuera denominarle Perlícaro, de que en ser murmurador de ventaja era perro ladrador (que el perro símbolo fue de la murmuración por el ladrar, como de la lisonja por el lamer), y en el trato era bícaro...
Etimología del nombre de Perlicaro

\footnotetext{
${ }^{10}$ Ibid., p. 267.

${ }^{11}$ Ibid.

${ }^{12}$ Ibid.

13 Es decir que se burla (da una vaya) de la función de cronista.

${ }^{14}$ Ibid.

15 Ibid., p. 270.

${ }^{16}$ Ibid., p. 272.
} 
La primera apostilla en el discurso narrativo de Justina es marcadamente culta, señal de que emana de la instancia introductora. Por su parte, en cuanto nace literalmente, Justina muestra la voluntad de «responder al reto de un fisgón» y delega en él la primera réplica en estilo directo ${ }^{17}$ :

—Sora Justiniga, sora pícara en requinta, ¿de cuándo acá da en ser cronicona de su vida y milagritos?
Matraca del fisgón que
fisga. Fisga de que la
misma Justina escriba su

En el texto en prosa, Perlícaro trata a Justina de «cronicona»-obsérvese el sufijo aumentativo despreciativo-, menospreciando el alcance de su «vida y milagritos»-sufijo diminutivo, igualmente despreciativo. La apostilla recurre al políptoton («fisgón» y «fisga» verbo y sustantivo), jugando con los sentidos de que ofrece el lexema «fisg-» busmear y burlarse ingeniosamente, dando lugar a una serie de oposiciones burlonas (es decir la «matraca») a la crónica («que la misma Justina escriba su vida»). La misma Justina ha dado la palabra a un personaje que pone en tela de juicio la necesidad de la historia y su propio papel de narradora, controlada a su vez por el autor de los apuntes marginales. El juego polifónico permite a la vez afirmar el poco crédito que se le debe dar al libro y justificar su necesidad, contraponiendo argumentos de autoridad y juegos de palabras: no es ninguna mujer ilustre pero a la hora de escribir su vida «Bien hace, que quizá no hallará otro historiador que contara la vida de una persona tan necesaria como secreta» ${ }^{18}$. Después de asentar, aunque de forma burlona, a Justina como instancia narrativa, sigue la matraca cuestionando en distintas variaciones el nacimiento literal del personaje llegado al libro a la edad adulta, sin atender a reglas compositivas aceptables. Antes de contestar a Perlícaro en un discurso oratorio en el que presenta objeciones a cada uno de los puntos ${ }^{19}$, prepara Justina el contraataque, dirigiéndose al lector ${ }^{20}$ :

Aquí puso mi paciencia el non plus ultra a la espera de la enfadosa matraca. Ya has oído lo que me dijo este alquilador de verbos. ¿Qué sería bueno que hiciese en este caso una matrona como yo? Enojarse a todo reventar. Y dirán: ¿de qué? Yo te lo diré, amigo preguntador, si me dejas tomar huelgo para el salto.

Pintase una mujer que finge las causas de un enojo, $y$ calla la verdadera.

La entrada en el juego interlocutivo del lector ficticio añade un estrato más a la estructura polifónica del texto, controlada en la apostilla por la voz autorial que instrumentaliza la digresión como una fuente de suspense (a la promesa de revelación en futuro en la oración de Justina corresponde el zeugma de la apostilla sobre la verdadera causa del enojo). Se inicia pues una conversación en varios grados: entre pícaros dentro de la ficción, entre la protagonista y el lector, entre el autor y el lector ${ }^{21}$.

\footnotetext{
${ }^{17}$ Ibid., p. 275.

${ }^{18}$ Ibid., p. 276. David Mañero Lozano indica el equívoco burlesco debido al empleo de los adjetivos necesaria y secreta, aplicables a la letrina.

${ }^{19}$ NúMERO SEGUNDO: De la contrafisga colérica / [Justina fisga del fisgón con mucha cólera, pero con mucha gracia, por el mismo orden que él fue fisgando della.], Ibid., p. 296.

20 Ibid., p. 288.

${ }^{21}$ Las apóstrofes al lector son numerosas a lo largo de la obra. Cabe destacar los dos grados de interlocución: Justina trata al destinatario con familiaridad (hermano, amigo, piadoso, cristiano, de mis ojos, letorcillo), tuteándolo de forma singular o colectiva; la instancia autorial designa tanto al personaje como al lector en tercera persona y sin adjetivación en la apostillas y aprovechamientos, se sitúa por encima de ambos.

He aquí la lista (la paginación remite a la edición digital de Enrique SUÁREZ FIGAREDO, http://users.ipfw.edu/jehle/cervante/othertxts/Suarez Figaredo PicaraJustina.pdf): «De aquí colegirás, letor cristiano...» en el capítulo comentado (p. 74); «Por aquí sacarás, lector benevirlo (digo, benévolo), la discreción de
} 
La palabra, polifónica y distribuida en diversos espacios textuales, hace entrar al lector dentro de una intriga digresiva, que favorece la multiplicación de los estratos textuales ${ }^{22}$. La discusión que se entabla en el umbral de la ficción es de corte metaficcional en la que apenas comenzada la acción queda suspendida como lo subraya la expresión de simultaneidad en el poema («Al comenzar Justina...»), después de la cual la acción permanece en estado embrionario. De hecho, la historia de los orígenes no llega hasta el Capítulo segundo «Del abolengo alegre» ${ }^{23}$, de nuevo demorada por una serie de consideraciones sobre la pertinencia de contarlos, terminando por afirmar explícitamente que Justina pertenece a la tradición picaresca porque conoce los cánones del género ${ }^{24}$ :

...para fundar su intento [la escritora que se intitula Pícara], debe probar que la picardía es herencia; donde no, será pícara de tres al cuarto.

\section{El buen picaro halo de serpor herencia.}

Tanto el texto como la apostilla recurren a estructuras de obligación para insistir en la condición necesaria de la estirpe picara de la protagonista ${ }^{25}$, abundando en el apelativo declinado en nombre propio, sustantivo y adjetivo en ambos géneros. Así pues, tras la evidente intención paródica, aparece que no es la diégesis lo que más importa sino la capacidad de reflexión que la escritura ofrece. La inclusión de las apostillas contribuye a la puesta en escena de la composición,

mi padre....» (p. 92); «Yo, hermano lector, ya adivino que en oyendo quién fue mi madre, te has de santiguar de mí como de la Bermuda.» (p. 93); «Así que, hermano lector, cada cual enseña lo que sabe...» (p. 98); «Paréceme que te leo los labios, hermano letor, y que me preguntas y me mandas que te diga muy en particular el discurso de mi vida y aventuras...» (p. 109); «Ay, hermano letor, mira con quién, para consolarme con decir: no estás conmigo!» (p. 145); «Duerme, hermano lector, que mañana amanecerá y quizá tendrás gana de leer más. [...] APROVECHAMIENTO [...] En especial, note el lector en qué paran romerías de gente inconsiderada...» (p. 165); «-Justina, adjetivad para peras. Acaba ya, hermano lector. Vete conmigo, que buena es mi compañía.» (p. 168); «APROVECHAMIENTO - Pondera, el lector, que los males crecen a palmos...» (p. 174); «Vaya conmigo el piadoso lector y no me tenga por boba, que yo me entendía. ¿Quieres saber por qué lo dije esto del platero?» (p. 200); «Hermano letor, ruégote que si no te duele la muela del seso, escuches un poco de sermón cananeo.» (p. 240); «Ruégote, letor de mis ojos, que esta vez y no más me hagas escurrir cuentos de vieja.» (p. 240); «Ya te cansará el leer los arrabales de mi leyenda; pues, ¿por qué no me lo decías antes, lector amigo?» (p. 254); «[Advertencia al lector] (p. 260); «Dirás, hermano lector: -Pues, Justina, cadónde apuntan los registros de ese breviario? Anda, déjame letorcillo, que en haciendo un pinico de predicadora, luego me tiras nabos.» (p. 278); «[Capta la atención al lector] Por tu vida, oyente mío, que aunque te parezca fuera de propósito, me escuches y juzgues si tengo yo razón en una cosa que te diré.» (p. 294); «[...] obras, de las cuales diré algo, no para escandalizar al lector, sino para que fíe poco de viejas ruines que parecen rezaderas y ejemplares y no relucen sino al candil del Diablo, y para que te guardes de tales.» (p. 330); «Dios nos dé salud a todos; a los lectores para que sean paganos, digo para que los paguen; y a mí para que cobre, y no en cobre...» (p. 384); «[Despídese del letor.] Adiós, piadosos lectores. Los cansados de leer mi historia, descansen. Los deseosos de el segundo tomo, esperen un poco, guardando el sueño a la recién casada.» (p. 398).

${ }^{22}$ La digresión aparece de hecho como una de las figuras más relevantes en La pícara Justina, lo cual asume la narradora de forma explícita: «Yo pienso que la bondad de las cosas no consiste tanto en la sustancia dellas cuanto en menudencias y accidentes de ornatos y atavíos. Ansí mismo, pienso yo que la bondad de una historia no tanto consiste en contar la sustancia della cuanto en decir algunos accidentes, digo acaecimientos transversales, chistes, curiosidades y otras cosas a este tono, con que se saca y adorna la sustancia de la historia; que ya hoy día lo que más se gasta son salsas, y aun lo que más se paga.» (citado por David MAÑERO LOZANO, «El "cotidiano dezir" de La picara Justina. Aproximación formal al estudio de comicidad popular en la literatura, española del Siglo de Oro», in eHumanista, 21, 2012, p. 182, URL: http://ujaen.aca demia.edu/DavidMa $\%$ C3\%B1eroLozano/Papers).

${ }^{23}$ La picara Justina, p. 130.

${ }^{24}$ Ibid., p. 318.

${ }^{25}$ Se repite la mención necesaria del origen en el mismo capítulo: «Mas por no torcer el orden de una generación tan importante, diré primero de mis abuelos machunos y hembrunos y luego diré de mis padres [...] llamáronme Justina porque yo había de mantener la justa de la picardía, y Díez, porque soy la décima esencia de todos ellos, cuanto y más la quinta.», Ibid., p. 327. 
visualmente materializada como una suerte de laberinto. En el camino sinuoso de la lectura se ofrecen una serie de claves en forma condensada.

\section{Control de la materia y concepto literal}

La estrategia de escritura desobedece en todo a lo lineal, oscilando entre la digresión y la variación. Los apuntes marginales condensan lo enunciado de otra forma que en los títulos, en los versos y en los aprovechamientos, sirviendo de mapa conceptual. El aspecto repetitivo de la técnica y redundante de los mensajes supone cierta circularidad sin excluir el efecto de sorpresa. Así como los esquemas métricos que encabezan los números son un repertorio formal siempre diferente (repetición estructural / sorpresa formal), la autorreferencialidad de las apostillas presenta también una serie de variaciones.

El control de la materia literaria por las instancias narradoras se manifiesta de forma espectacular en la organización del final de la obra. Si a la entrada del texto se multiplican las etapas en una suerte de incipit hipertrofiado, la despedida se materializa en distintos niveles aunque de forma más concentrada. La primera etapa combina la despedida explícita del personaje con la apostilla correspondiente ${ }^{26}$ :

Adiós, piadosos lectores. Los cansados de leer mi historia, descansen. Los deseosos de el segundo tomo, esperen un poco,

Despidese del lector. guardando el sueño a la recién casada.

La tópica promesa de más aventuras en un «segundo tomo» se precisa con la inclusión de los futuros títulos «En cuyo primer libro me llamo la alojada, en el segundo la viuda, en el tercero la mal casada y en el cuarto la pobre. Libros son de poco gasto y mucho gusto» ${ }^{27}$.

Dios nos dé salud a todos; a los lectores para que sean paganos, digo para que los paguen; y a mí para que cobre, y no en cobre, Pide paga. aunque si trae cruces y es de mano de cristianos lo estimaré en lo que es y pondré donde no lo coman ratones.

En lo que a la voz del personaje se refiere, no hay final propiamente dicho sino despedida pasajera con promesa tópica de más aventuras, mientras que la voz narrativa cierra el texto aludiendo a su intención satirizante. La última apostilla («Pide paga») reclama la retribución del público como al final de una función.

El desdoblamiento del «yo» en vOz narrativa y voz autorial necesita dos cierres, para que ambas instancias se despidan explícitamente. El propio autor insiste en ello en el último aprovechamiento y en el párrafo conclusivo: 
por instantes crece con la ayuda del tiempo y fuerza de la ociosidad. Verás ansi mismo cómo la mujer que una vez. echa al tranżado el temor de Dios, de nada gusta, si no es de aquello en que le contradice, siendo ansí que sin Dios no hay cosa que merezca nombre de gusto, sino de pena mayor que los mil infiernos. Mas como Dios sea infinitamente bueno, de los males saca bienes para los suyos y para su divino nombre, bonra y gloria. 28

En el párrafo conclusivo se identifica el autor como voz en primera persona que reivindica la creación de la obra («estatua... que he fabricado»), en espejo a los textos liminares. El sistema interlocutivo se establece con el lector, al que se tutea en verbos en futuro («echarás de ven», «verás»), lo cual resulta curioso a la hora de concluir, a menos que el mismo autor tome en cuenta que la lectura de la obra no ha de ser lineal. Finalmente el aspecto didáctico-moral («Dios... de los males saca bienes») enlaza con el aprovechamiento del primer número del primer capítulo cuando se sugiere el paralelo entre «el Autor de naturaleza»y «el autor» del libro, sin mayúscula. La simetría de las referencias y la estructura del cierre en puzle muestra que el mapa conceptual de la obra es el del control supremo de la instancia autorial.

El artificio literario, la multiplicidad de las formas textuales dentro de una misma obra, resulta visible, escenificada de forma que puede tratarse de un escudo retórico dentro de la más pura tradición satírica: la excusa de reformar moralmente sirve para expresarse libremente. El párrafo conclusivo, situado al margen de la obra y tipográficamente separado de ésta, vuelve a enunciar en forma de variación la conformidad moral del libro:

Todo lo que en este libro se contiene, sujeto a la corrección de la Santa Iglesia Romana y de la Santa Inquisición. Y advierto al lector que siempre que encontrare algún dicho en que parece que hay un mal ejemplo, repare que se pone para quemar en estatua aquello mismo, y en tal caso, se recorra al aprovechamiento que he puesto en el fin de cada número y a las advertencias que hice en el prólogo al lector, que si ansí se hace, sacarse ha utilidad de ver esta estatua de libertad que aquí he pintado, y en ella, los vicios que hoy día corren por el mundo. Vale.

\section{LAUS DEO 29}

La expresión con la cual designa al personaje epónimo y al mismo libro por metonimia es la de «estatua de la libertad», volviéndose la obra una suerte de alegoría de la escritura. A modo de apostilla ampliada, la invitación a «quemar en estatua» cualquier vicio representado en los diferentes capítulos, alusión a la Inquisición antes citada, evoca también a «la estatua», la propia Justina y/o el libro en sí, invitando a un simbólico auto de fe si no conviene lo leído, como en un escrutinio autocrítico asumido. La alusión final a «la pintura de los vicios que hoy día corren por el mundo» remite claramente a la sátira, pero la escritura multidireccional -obsérvense las invitaciones a recorrer los aprovechamientos y el prólogo-, combinatoria, redunda en la burla de la propia obra, en un juego de espejos múltiples.

\section{Conclusión: lo marginal como fórmula literaria}

El autor, próximo a la postura del artista «levantado en el aire» que Valle-Inclán identifica como tan española ${ }^{30}$, participa de la renovación literaria de los albores del siglo XVII. La orquestación textual de La picara Justina podría plasmarse en el siguiente esquema:

\footnotetext{
${ }^{28} \mathrm{Ibid}$.

29 Ibid., p. 970-971. Se retoman en variación el yo-creador, las evocaciones del lector, el enlace con los aprovechamientos y el prólogo.
} 


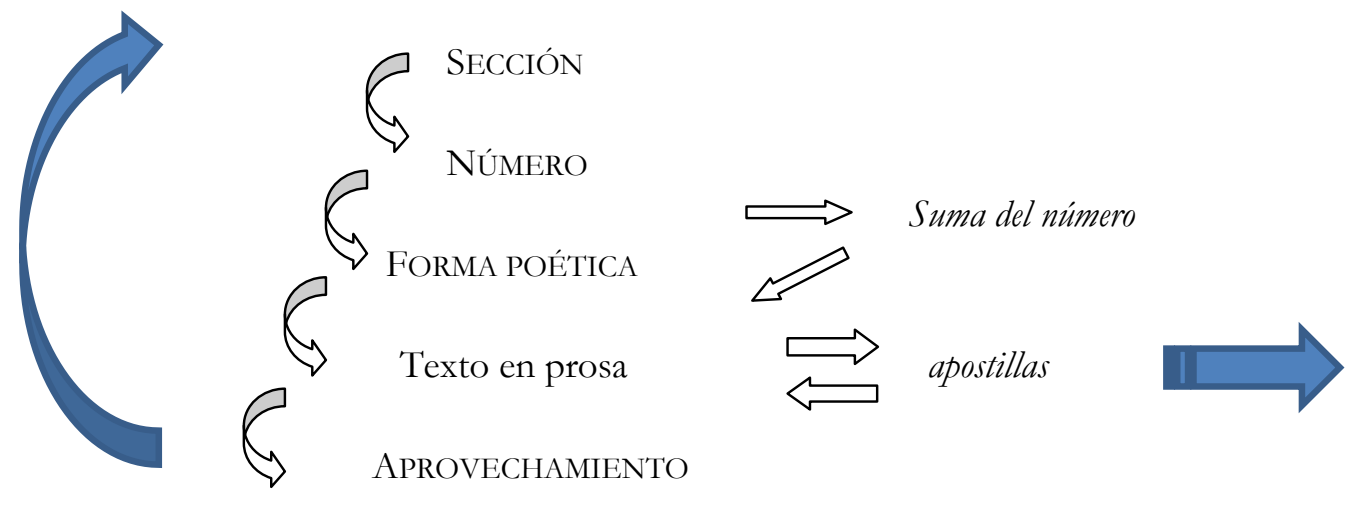

El espacio marginal, entendido al pie de la letra, refleja y condensa lo marginal de la escritura de la obra, como una suerte de concepto literal. El mundo narrativo de Justina es el de la picaresca, explícitamente reiterado como tal y objeto de la escritura. Poner en escena lo marginal puede consistir en encontrar una fórmula literaria extra-ordinaria. Lo marginal se transforma así en una suerte de redundancia entre contenido y forma: el margen del texto sirve para recordar que se trata de una fabricación, un anti-exemplum. La sustancia narrativa -la vida de Justina- se sitúa fuera de las normas morales y fuera de la normas de escritura.

Aparece una dimensión lúdica de la obra que juega consigo misma, con sus códigos y tradiciones. Los efectos visuales, la fragmentación, le confieren un estatus singular en el paisaje literario aurisecular. El espacio marginal favorece una lectura hipertextual que combina espacio autorreferencial y espacio extra-referencial ${ }^{31}$.

\footnotetext{
${ }^{30}$ La cita, famosísima, en la que el autor explica el origen del esperpento se publica en la entrevista que mantuvo Valle-Inclán con Martínez Sierra en el diario $A B C$ del 7 de diciembre de 1928: http://hemeroteca.abc.es/nav/Navigate.exe/hemeroteca/madrid/abc/1928/12/07/003.html.

31 Sería de gran interés una edición digital que pudiera incluir la hipervinculación, pues además de facilitar el acceso a las notas eruditas que ya aportan las ediciones en papel, podrían relacionarse las apostillas con referencias externas, lo cual la excelente edición de David Mañero Lozano no propone por limitaciones evidentes del soporte.
} 